\title{
(2) OPEN ACCESS \\ Checkpoint inhibitors and radiotherapy in refractory malignant melanocytic schwannoma with Carney complex: first evidence of efficacy
}

\author{
Jyoti Bajpai 다, ${ }^{1}$ Akhil Kapoor 다, ${ }^{1}$ Rakesh Jalalii, ${ }^{2,3}$ Mrinal M Gounder ${ }^{4,5}$
}

\begin{abstract}
- Additional online supplemental material is published online only. To view, please visit the journal online (http://dx.doi.org/10.1136/ bcr-2020-240296).

${ }^{1}$ Medical Oncology, Tata Memorial Hospital, Tata Memorial Centre, Homibhabha National Institute, Mumbai, Maharashtra, India ${ }^{2}$ Radiation Oncology, Tata Memorial Centre,Tata Memorial Centre, Homibhabha National Institute, Mumbai, Maharashtra, India

${ }^{3}$ Apollo Proton Cancer Centre, Chennai, India

${ }^{4}$ Medicine, Memorial Sloan Kettering Cancer Center, New York, New York, USA

${ }^{5}$ Medicine, Weill Cornell Medical College, New York, New York, USA
\end{abstract}

Correspondence to Dr Mrinal M Gounder; gounderm@mskcc.org

Accepted 9 April 2021

\section{Check for updates}

(c) BMJ Publishing Group Limited 2021. Re-use permitted under CC BY-NC. No commercial re-use. See rights and permissions. Published by BMJ.

To cite: Bajpai J, Kapoor A, Jalali $\mathrm{R}$, et al. BMJ Case Rep 2021;14:e240296. doi:10.1136/bcr-2020240296

\section{SUMMARY}

Melanocytic schwannoma (MS) is a rare nerve sheath tumour characterised by melanin-producing neoplastic schwann cells that typically affects the posterior spinal nerve roots. We report an ultrarare case of recurrent/ metastatic MS associated with Carney complex in a young woman with family history of breast cancer. This highlights the novel approach of combined checkpoint inhibitors (CPI) and radiotherapy. The patient was initially treated with Nivolumab along with concurrent external beam radiotherapy. There was sustained clinical benefit achieved for over 15 months with preserved quality of life. Addition of Ipilimumab, which she tolerated reasonably well, helped to control the progressive disease again for another 12 months. She harboured a rare PRKAR1A R228 mutation (Carney complex) and received appropriate targeted therapy. She survived for 51 and 35 months from her initial diagnosis and start of $\mathrm{CPI}$, respectively, which to the best of our knowledge is the longest documented survival in this rare entity.

\section{BACKGROUND}

Melanocytic schwannoma (MS), first described in 1932, is an extremely rare nerve sheath tumour characterised by melanin-producing neoplastic schwann cells that typically affects the posterior spinal nerve roots. There are fewer than 200 cases reported in the literature. Some have reported an indolent behaviour while others have reported increased rates of local recurrence and metastatic disease; where the median overall survival is 11 months. ${ }^{1-5}$ MS is classified into psammomatous and non-psammomatous types, where the psammomatous type of MS is association with Carney complex. ${ }^{3}$

Due to the relatively small numbers and variable outcomes, there is a paucity of evidence to guide regarding treatment recommendations of these tumours. Surgery with or without adjuvant radiation is considered standard of care in localised disease whereas cytotoxic chemotherapy is considered in unresectable disease, although with poor efficacy. ${ }^{2}$ We report an extremely rare case of recurrent and metastatic MS associated with Carney complex. The focus of the current case report is to highlight a novel combinatorial approach of checkpoint inhibitor (CPI) and radiotherapy (RT) achieving a prolonged clinical benefit. Furthermore, this also provides food for thought to look for precision therapy-based approach in this rare case associated with an ultra-rare mutation. This may serve as the basis for systematically exploring CPI in this data-free zone.

\section{CASE PRESENTATION}

A young active Indian woman in her early thirties presented with worsening although intermittent back pain for 6 months. This was responsive to symptomatic treatment and was not disturbing with her mobility or any other activity of daily life. The important clinical timelines of this patient are shown in figure 1 . Her medical history was notable for well-controlled bronchial asthma and a family history of breast cancer in her mother at age 60 years. Physical and neurological examination was unremarkable. On investigations, MRI scan revealed a dumb-bell shaped mass, $2 \times 1.5 \times 1.2 \mathrm{~cm}$ within left L3-4 intervertebral foramens highly suggestive of a schwanomma (figure 2A). Since she was not much symptomatic and radiology was suggestive of benign schwannoma, after a detailed discussion with patient and family, she was kept under active surveillance and supportive care. There was no histological confirmation done at this point.

She was symptom free for about 6 months when she started having pain radiating to her left lower limb. Gradually, she started experiencing restriction in mobility; with objective signs in the form of restricted straight leg raising of only $10^{\circ}$ in left lower limb. The repeat MRI scan suggested that the lesion had increased in size to $2 \times 2.5 \times 1.9 \mathrm{~cm}$. She underwent (first surgery) a L3-L4 foraminotomy and gross total excision of the lesion (R0 resection) without electrophysiological monitoring. A scan done after 3 days of surgery revealed only postoperative changes.

\section{INVESTIGATIONS}

Histopathology showed a relatively well circumscribed, extensively pigmented, nodule with areas of tumour cells invading the perineurium (figure 3A). The tumour cells were spindle to ovoid shaped with large vesicular nuclei, prominent nucleoli, abundant melanin pigment deposits, and showed no necrosis with Ki-67 of 1\%-2\% (figure 3B). The tumour cells tested positive for both S-100 and HMB-45 on immunohistochemistry whereas the laminin and collagen type IV staining showed focal positivity of the basement membrane consistent with a diagnosis of MS. Based on the histological features and no evidence of residual disease, she was kept on close observation. 


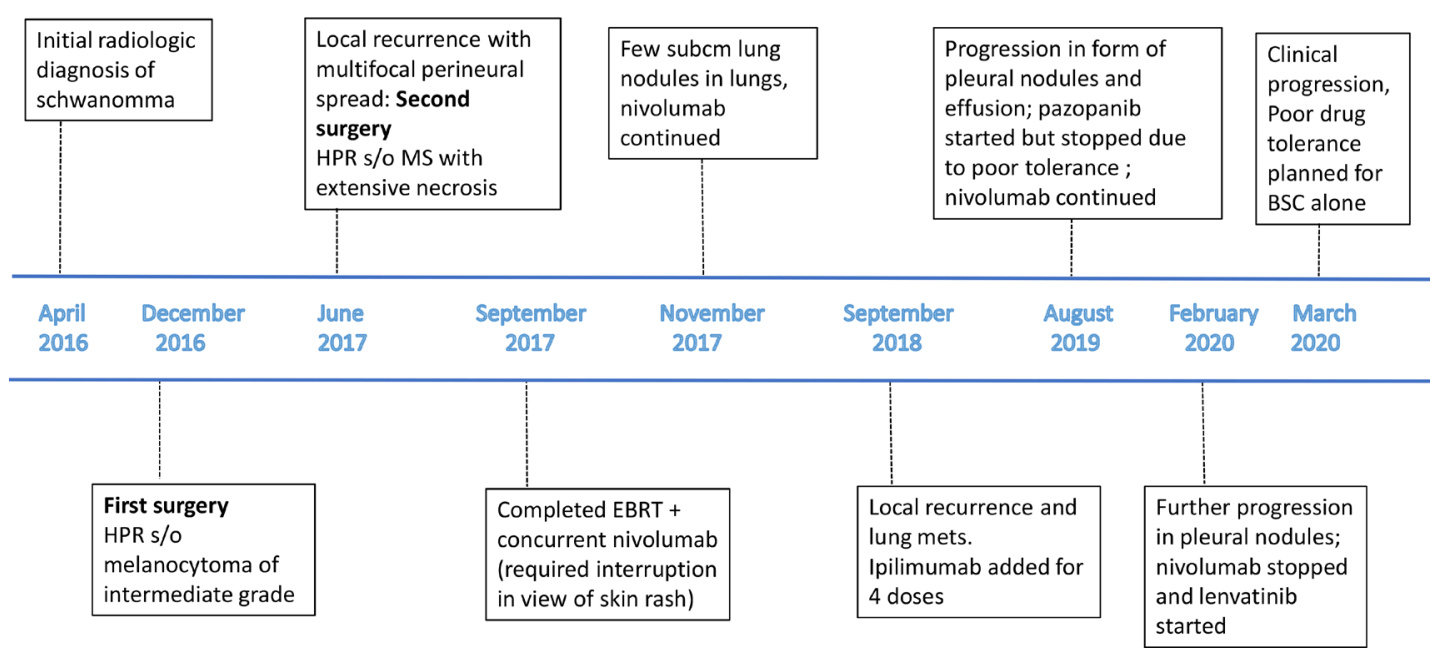

Figure 1 Important timelines. EBRT, external beam radiotherapy; MS, melanocytic schwannoma.

On a routine surveillance MRI scan done 2 months after the first surgery (10 months from her initial diagnosis), a recurrent lesion $9 \times 7 \times 5 \mathrm{~mm}$ was noticed at the same site (figure $2 \mathrm{~B}$ ). However, as the patient was completely asymptomatic, she was continued on close observation. Repeat MRI scan after 3 months interval showed new onset multiple small nodules with similar morphology in left posterior paraspinal soft-tissues and marginal increase in the pre-existing lesion (from 9 to $11 \mathrm{~mm}$ ).

\section{TREATMENT}

She underwent a second surgery in the form of a radical en bloc resection of the left paraspinal mass with resection of the left $\mathrm{L} 3$, L4 hemilamina, left facet joint and the resection of the affected left L3 nerve root, L3 ganglion and left psoas deposits. This was followed by right L2-3-4 pedicle screw fixation for stabilising the spine. This was carried out under intraoperative monitoring via motor evoked potentials, somatosensory evoked potentials and electromyography. The margins were negative; however, there were melanin deposits around the neural bundles which could not be addressed surgically ( $\mathrm{R}+$ resection). Online supplemental figure $1 \mathrm{~A}-\mathrm{G}$ and $2 \mathrm{~A}, \mathrm{~B}$. The patient recovered well from the procedure and subtle weakness of the left knee extensors and small area of sensory loss in the L3 distribution. However, she was independently ambulant and could carry out all her previous levels of activities with minimal dysfunction.

Histopathology revealed recurrent, malignant MS aggressive features in the form of increased mitoses (atypical mitotic figure $5 / 10$ per high power field) and increased Ki-67 of 5\%, pleomorphism, and areas of coagulative necrosis. The close differential considered was melanoma. All the margins were free. The tissue was depleted and further molecular and PD L1 staining could not be attempted. At this time point, the patient presented

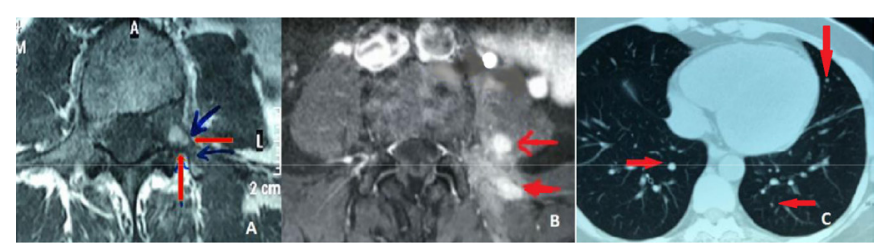

Figure 2 MRI arrow showing lesion at L3-4 vertebra at baseline: (A) recurrence of the lesion at left L3-4 foramen (B) and CT thorax showing subcentimeter nodules in the lung parenchyma at the time of recurrence (C). to the tertiary care cancer centre. CT chest demonstrated new onset, subcentimetre $(2-3 \mathrm{~mm})$, indeterminate lung nodules (figure 2C).

In the absence of any standard of care recommendations, especially for patient with aggressive recurrent disease and melanotic nature of tumour, the multidisciplinary tumour board (MDT) recommended a course of radiation with concurrent CPI. The patient was started on nivolumab ( $3 \mathrm{mg} / \mathrm{kg}$, biweekly) concurrently with adjuvant external beam radiotherapy (EBRT), at a total dose of $50 \mathrm{~Gy}$ in 25 fractions to the spine. After two doses of nivolumab with concurrent EBRT, she developed grade 2 skin rash and grade 1 diarrhoea. She was treated with prednisolone in tapering dose and interruption of nivolumab for 2 weeks. Following radiation, she remained on biweekly nivolumab.

She was completely asymptomatic and tolerated Nivolumab well; a response assessment FDG-PET scan after six doses of Nivolumab (3 months) showed stable 2-4 mm, non-FDG avid, indeterminate lung nodules. She was continued on nivolumab with excellent tolerance and quality of life (QOL). After 15 months of maintenance nivolumab, although she was asymptomatic, there were signs of radiographic disease progression with enlarging lung nodules and local recurrence in the lumbar spine at the level of L2-L3 and a $1.6 \mathrm{~cm}$ ilio-psoas muscle mass. A repeat biopsy of the lung nodule revealed MS with aggressive features including pleomorphism, increased mitotic activity and areas of coagulative necrosis (figure $3 \mathrm{C}$ ).

Ipilimumab was added at a dose of $1 \mathrm{mg} / \mathrm{kg}$, every 3 weekly for four doses along with nivolumab, given at dose of $3 \mathrm{mg} /$

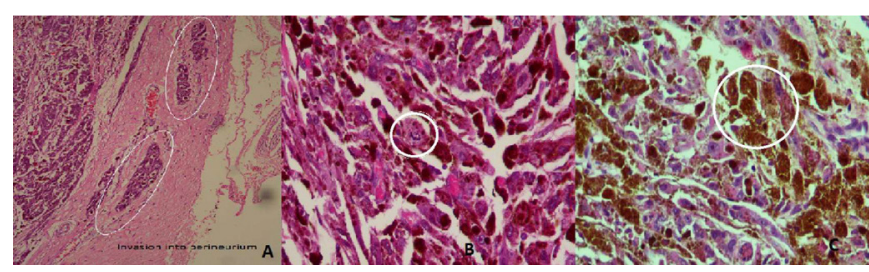

Figure 3 Histopathology slide pictures showing the areas in white circle in (A) marking the invasion of tumour cells in perineurium, (B) ovoid cells with large vesicular nuclei and prominent nucleoli; this along with immunohistochemistry studies was suggestive of melanocytic schwanomma, (C) increased mitotic activity and areas of coagulative necrosis suggestive of transformation to aggressive variant of melanocytic schwanomma. 
kg 3 weekly. After the four doses of ipilimumab, nivolumab was continued in same dose and schedule. The disease was under control for additional 7 months with preserved QOL. Subsequently, the patient developed chest pain and imaging showed new onset pleural nodules, effusion and iliopsoas nodules were noted. At this point, we explored next generation sequencing (Foundation-One CDx, Foundation Medicine, Cambridge, Massachusetts, USA) on the iliopsoas nodules which revealed KDR N156D and PRKAR1A $R 228$ mutations. The tumour mutation burden was low (two mutations/Mb) and microsatellite instability was not high. Approximately $10 \%-15 \%$ of the tumour cells showed positivity for PDL1 (clone: SP263; Ventana). The MDT decision was to start the patient on Pazopanib $(800 \mathrm{mg})$ to target the potential driver mutation in KDR. After a week of pazopanib, the patient developed drug related, severe oral mucositis, dyspnoea, fatigue and fever. The patient declined further on continuation of pazopanib. Therapy was reverted to nivolumab for three additional cycles. In view of further progression in pleural nodules, she was started on lowdose lenvatinib with plan of gradual escalation depending on tolerance. However, after 3 weeks of lenvatinib, the patient started deteriorating clinically with worsening chest symptoms, severe fatigue and malaise with documented radiographic progression. The patient declined further and a decision was taken to discontinue any cancer-directed therapy and provide best supportive care alone.

\section{OUTCOME AND FOLLOW-UP}

Overall, the patient was survived for 51 and 35 months from her initial diagnosis and start of CPI, respectively, before she succumbed to her illness. She did, however, maintain a good QOL for the larger part of the treatment.

\section{DISCUSSION}

The MS is a rare diagnosis and association with Carney complex is even rarer. Clear communication between various specialists, and close attention to histologic findings are crucial. ${ }^{6}$ MS can manifest as a spectrum of benign to malignant disease and the course is unpredictable necessitating long term follow-up. ${ }^{4}$ In a preclinical study Eberting et al, reported that local growth at the injection site may occur after the development of regional metastases. ${ }^{7}$

Our case describes an extremely rare scenario of transformation from atypical melanocytoma to MS with Carneys complex. The tumour subsequently acquired aggressive histological features with each recurrence including pleomorphism, increased mitotic activity and areas of coagulative necrosis, accompanied by aggressive clinical behaviour.

MS is a variant of schwanomma and is usually circumscribed and encapsulated. It is characterised microscopically to harbour spindle or epithelioid cells along with pigmented granules; mitotic figure being a rare finding. ${ }^{8}$ The features that differentiates MS from a classic schwannoma include absence of a well-defined capsule, distinct areas of Antoni $\mathrm{A} / \mathrm{B}$, presence of melanin and psammoma bodies. ${ }^{9}$ The important differential is malignant melanoma and differentiating features include abundant cytoplasm, imperceptible cell border and a low proliferative index. ${ }^{10}$ There may be obscuration of cellular details by the melanin pigment which might lead to overestimation of Ki-67. ${ }^{10}$

Torres-Mora et al have shown that only increased mitotic activity ( $\geq 2$ mitotic figures/10 HPF) predicted aggressive behaviour. ${ }^{4}$ However, contrary to this, in another study more than half of the MS patients subsequently metastasised despite initial lack of high mitotic activity with an overall distant metastasis rate of $26 \% .{ }^{11}$ The reported local and distant failure rates are $35 \%$ and $42 \%$ respectively with a dismal median OS of around 11 months. ${ }^{4}$

In Carney's series of 31 patients, 17 (55\%) MS patients showed evidence of Carney complex and those with multiple MS had higher propensity for this association. ${ }^{3}$ In this study, 33\% tumours had loss of the Carney complexassociated tumour suppressor gene PRKAR1A, located over chromosome 17p23-24. Similarly, Horvath et al reported this mutation in $40 \%$ of familial and sporadic patients with Carney complex. ${ }^{12}$ Some studies have reported the mutation or loss of heterozygosity of this gene in various neoplasms associated with Carney complex ${ }^{13}$ such as, pancreatic ductal and acinar neoplasm, ${ }^{14}$ and pigmented epithelioid melanocytoma but not in melanoma or other melanocytic lesions. ${ }^{15}$ Notably, the loss of PRKAR1A expression suggests a link to Carney complex type 1 , even when classical features are absent. ${ }^{4}$ Besides, PRKAR1A gene is also associated with breast cancer. ${ }^{16}$ Thus, the PRKAR1A mutation found in this patient with family history of breast cancer in her mother strongly suggest the diagnosis of MS associated with Carney complex. We were unable to confirm whether this loss of tumour suppressor gene is germline and inherited.

The optimal treatment for MS remains undefined with complete tumour resection being the desired initial treatment. However, due to extensive local infiltration, this is usually not possible. The nuances in neurosurgical techniques and clinical approach are reported distinctly. ${ }^{17}$

Our patient's disease progression, aggressive histology, melanotic nature of the tumour and suspected lung metastases, helped the MDT to recommend CPI and RT despite no such treatment described in literature. A parallel was drawn from a recent study that combined nivolumab with multifraction stereotactic radiosurgery which showed a strong synergistic effect in patients with melanoma and brain metastases. ${ }^{18}$

This case was unique on several accounts. To the best of our knowledge, this is the first case of aggressive MS with PRKAR1A R228 mutation and Carney complex that had transformed from an atypical melanocytoma. She achieved prolonged clinical benefit with novel combinational approach of CPI and RT for over 15 months with preserved QOL. Addition of Ipilimumab, which she tolerated reasonably well, helped to control the progressive disease again for another 12 months.

Overall, the patient was survived for 51 months after the diagnosis of MS and for large part of it, she did maintain good QOL. This unprecedented long survival was achieved by concurrent CPI and RT in initial phase followed by CPI maintenance. This provides a strong rationale for potentially testing the role of immunomodulation along with RT for possible abscopal effect in this orphan disease. ${ }^{19}$

\section{CONCLUSIONS}

Immune checkpoint inhibitor has shown durable clinical benefit and prolongation of survival in this rare and extremely challenging case. This is the first evidence of activity of CPI with RT in this ultrarare case of MS with Carney complex and merits exploration in future studies for reproducibility with potentially practice changing implications. 


\section{Patient's Perspective}

My wife was diagnosed with an extremely rare entity melanotic schwannoma. Despite, being a medical doctor, I was not aware of this entity ever. What was perceived as a nonspecific back pain later turned out to be a spectrum of schwannomas to melanotic schwannoma and with each subsequent recurrence 'a wolf inside sheep's skin' and we learnt how unpredictable life can be!

She was treated with a novel kind of treatment including the immunotherapy and radiotherapy. There were discussions among various doctors including from various disciplines and overseas. The story was associated with big dilemmas all the time; there was a challenge in diagnosing at each recurrence then choosing the best way to treat especially with incremental increase in severity.

However, our satisfaction was that we were very much aware of the doctors working together right from the beginning and throughout. They would tend to discuss with us all the details and we always felt involved in all the decisions.

After her diagnosis we realised more emphatically, how much it is important to have many different specialists involved and work together in care of such complex and rare cases to get out the best possible outcomes.

It was a fear of unknown as this was an unknown territory and understandably, we were worried about the outcomes; however, our satisfaction is that she attained the longest survival in this difficult to treat malignancy and for the larger part of this treatment she enjoyed a good quality of life.

She was an extremely brave woman and our message to the patients and families of rare diseases is to never lose hope and fight the disease as a team with treating doctors.

Learning points

- Melanotic schwannoma is a rare disease and is essentially a data-free zone especially those with association of Carney complex.

- There may be a spectrum of evolution from schwannoma to melanotic schwannoma with incremental aggressive behaviour in each subsequent recurrence.

- A multidisciplinary team approach was required to direct and achieve appropriate management including molecular tumour boards. Rare and challenging cases such as this, require careful treatment prioritisation, planning and collaborations among various specialists across the geographical borders.

- There is an evidence of activity of combined checkpoint inhibitors with radiotherapy in melanotic schwannomas which suggest role of immunomodulation in this rare and challenging entity and merits exploration in future studies.

\section{Twitter Jyoti Bajpai @JyotiBajpai01 and Akhil Kapoor @akhilkapoor1}

Acknowledgements The authors would like to acknowledge the contributions of Dr. Sridhar Epari, Department of Pathology, Tata Memorial Hospital, Mumbai and Dr. Hameed Meera, Department of Pathology, Memorial Sloan Kettering Cancer Centre, NY for providing detailed review of the pathology images and team of Neurosurgeons led by Dr. Deopujari at Bombay Hospital and Medical Research Centre, Mumbai.The authors are extremely grateful to the patient and family for their trust and support throughout the management and providing the necessary details and consent for the publication of this manuscript.
Contributors JB: conception and design, all treatment decisions, treatment planning and executions, primary patient care, first draft of the manuscript, final draft of the manuscript. AK: first draft of the manuscript, final draft of the manuscript. $\mathrm{RJ}$ : primary patient care, treatment decisions, final draft of the manuscript. MMG: conception and design, treatment decisions, final draft of the manuscriptAll authors read and approved the final manuscript.

Funding The authors have not declared a specific grant for this research from any funding agency in the public, commercial or not-for-profit sectors.

Competing interests Mrinal Gounder reports consulting fees from pharmaceutical companies: Ayala, Bayer, Boehringer Ingelheim, Daiichi, Epizyme, Karyopharm, Springworks, Tracon and TYME; consultation fees from: Flatiron Health, Guidepoint, GLG, Medscape, More Health, Physicians Education Resource and touchIME; royalty fees from UpToDate; patents with MSKCC (GODDESS PRO); uncompensated research with Foundation Medicine, Rain and Athenex. Grants from Food and Drug Administration (R01 FD005105) and the National Cancer Institute, National Institutes of Health (P30CA008748) — core grant (CCSG shared resources and core facility).

\section{Patient consent for publication Obtained.}

Provenance and peer review Not commissioned; externally peer reviewed.

Open access This is an open access article distributed in accordance with the Creative Commons Attribution Non Commercial (CC BY-NC 4.0) license, which permits others to distribute, remix, adapt, build upon this work non-commercially, and license their derivative works on different terms, provided the original work is properly cited and the use is non-commercial. See: http://creativecommons.org/ licenses/by-nc/4.0/.

\section{ORCID iDs}

Jyoti Bajpai http://orcid.org/0000-0001-7657-3460

Akhil Kapoor http://orcid.org/0000-0001-6006-2631

\section{REFERENCES}

1 Millar WG. A malignant melanotic tumour of ganglion cells arising from a thoracic sympathetic ganglion. J Pathol Bacterio/ 1932;35:351-7.

2 Zhang H-ying, Yang G-hua, Chen H-jiao, et al. Clinicopathological, immunohistochemical, and ultrastructural study of 13 cases of melanotic schwannoma. Chin Med J 2005;118:1451-61.

3 Carney JA. Psammomatous melanotic schwannoma. A distinctive, heritable tumor with special associations, including cardiac myxoma and the Cushing syndrome. Am J Surg Pathol 1990;14:206-22.

4 Torres-Mora J, Dry S, Li X, et al. Malignant melanotic schwannian tumor: a clinicopathologic, immunohistochemical, and gene expression profiling study of 40 cases, with a proposal for the reclassification of "melanotic schwannoma". Am J Surg Pathol 2014:38:94-105

5 Kinnen F, Fleck SK, Baldauf J, et al. Primary leptomeningeal melanocytic tumors of the spine: report of two cases and review of the literature. World Neurosurg 2019:\$18788750(19)30096-8

6 Topf MC, Pham QH, D'Souza JN, et al. Pigmented melanotic schwannoma of the neck: report of 2 cases and review of the literature. Ear Nose Throat J 2019;98:102-6.

7 Eberting CLD, Shrayer DP, Butmarc J, et al. Histologic progression of B16 F10 metastatic melanoma in C57BL/6 mice over a six week time period: distant metastases before local growth. J Dermato/ 2004;31:299-304.

8 Chakravarthy $\mathrm{H}$. Melanotic cyst of L5 spinal root: a case report and review of literature. Asian J Neurosurg 2012;7:217-9.

9 Lin Y-F, Hsi S-C, Chang J-L, et al. Intrapulmonary psammomatous melanotic schwannoma. J Thorac Cardiovasc Surg 2009;137:e25-7.

10 Choi S-E, Cha YJ, Kim J, et al. A rare case of aggressive melanotic schwannoma occurred in spinal nerve of a 59-year-old male. J Pathol Trans/ Med 2017:51:505-8.

11 Vallat-Decouvelaere AV, Wassef M, Lot G, et al. Spinal melanotic schwannoma: a tumour with poor prognosis. Histopathology 1999;35:558-66.

12 Horvath A, Bertherat J, Groussin L, et al. Mutations and polymorphisms in the gene encoding regulatory subunit type 1-alpha of protein kinase A (PRKAR1A): an update. Hum Mutat 2010;31:369-79.

13 Kim M-J, Choi J, Khang S-K, et al. Primary Intraosseous melanotic schwannoma of the fibula associated with the Carney complex. Pathol Int 2006;56:538-42.

14 Gaujoux S, Tissier F, Ragazzon B, et al. Pancreatic ductal and acinar cell neoplasms in Carney complex: a possible new association. J Clin Endocrinol Metab 2011;96:E1888-95.

15 Zembowicz A, Knoepp SM, Bei T, et al. Loss of expression of protein kinase A regulatory subunit 1alpha in pigmented epithelioid melanocytoma but not in melanoma or other melanocytic lesions. Am J Surg Pathol 2007;31:1764-75.

16 Bossis I, Stratakis CA. Minireview: PRKAR1A: normal and abnormal functions. Endocrinology 2004;145:5452-8.

17 Shaikh S, Gupta G, Mohanty C. Spinal nerve root extradural melanocytoma progressing to malignant melanoma: a case report with review of literature. Asian $J$ Neurosurg 2021. 
18 Minniti G, Anzellini D, Reverberi C, et al. Stereotactic radiosurgery combined with nivolumab or ipilimumab for patients with melanoma brain metastases: evaluation of brain control and toxicity. J Immunother Cancer 2019;7:102
19 Yilmaz MT, Elmali A, Yazici G. Abscopal effect, from myth to reality: from radiation oncologists' perspective. Cureus 2019;11:e3860.

Copyright 2021 BMJ Publishing Group. All rights reserved. For permission to reuse any of this content visit

https://www.bmj.com/company/products-services/rights-and-licensing/permissions/

BMJ Case Report Fellows may re-use this article for personal use and teaching without any further permission.

Become a Fellow of BMJ Case Reports today and you can:

- Submit as many cases as you like

Enjoy fast sympathetic peer review and rapid publication of accepted articles

- Access all the published articles

Re-use any of the published material for personal use and teaching without further permission

Customer Service

If you have any further queries about your subscription, please contact our customer services team on +44 (0) 2071111105 or via email at support@bmj.com.

Visit casereports.bmj.com for more articles like this and to become a Fellow 